\title{
Migration and Pollution Control of Chlorinated Hydrocarbons in Groundwater System of Eastern Jinan
}

\author{
Zhang shuiaji ${ }^{1}$, Du Wenfeng ${ }^{1}$, Liu Zhengwen ${ }^{2}$, and Gu Xiaoyu ${ }^{1}$ \\ ${ }^{1}$ China University of Mining and Technology Beijing Campus \\ ${ }^{2}$ The First Exploration Team of Shandong Coalfield Geology Bureau
}

November 14, 2021

\begin{abstract}
The groundwater system is polluted by chlorinated hydrocarbon pollution in eastern Jinan, Shandong province, China, exceeding the limit of pollutants concentration in class III of Groundwater Quality Standards (GQS, GB/T 14848-2017). In order to improve the current situation of chlorinated hydrocarbon pollutants in groundwater system of eastern Jinan, the optimization study of the pollution control is carried out. In this paper, the pollutant of carbon tetrachloride in groundwater system is taken as the main research object. By using GMS numerical simulation software to establish the solute transport model of carbon tetrachloride. The simulation results illuminate that with the passage of time, the concentration of carbon tetrachloride decreases, but the acreage of pollution plume in groundwater still has little change, and it is hard to reach the limit standard of $2.0 \mathrm{\mu g} / \mathrm{L}$ in class III of GQS within a short time. Sequentially, on the basis of simulation model, the optimization of pumping and injection wells is conducted in the pollution control field of research region. The results turn out that the layout of 8 pumping and 5 injection wells has the best control effect of carbon tetrachloride in groundwater system, the pollutant concentration reached the limit standard of $2.0 \mu \mathrm{g} / \mathrm{L}$ in only $1187 \mathrm{~d}$, and the acreage of pollution plume in control field reduced from $21.80 \mathrm{~km} 2$ to $12.21 \mathrm{~km} 2$. In summary, through the optimal pollution control scheme of carbon tetrachloride, the time for pollutant concentration to reach $2.0 \mu \mathrm{g} / \mathrm{L}$ has been reduced, and the acreage of pollution plume has been effectively controlled. This work further investigates the promoting effect of injection wells on hydraulic control of groundwater pollution, which can accelerate the circulation of the groundwater system and save the treatment time, providing a relatively practical way for the prevention and control of chlorinated hydrocarbon pollutants.
\end{abstract}

\section{Hosted file}

Text.docx available at https://authorea.com/users/446102/articles/545432-migration-andpollution-control-of-chlorinated-hydrocarbons-in-groundwater-system-of-eastern-jinan 

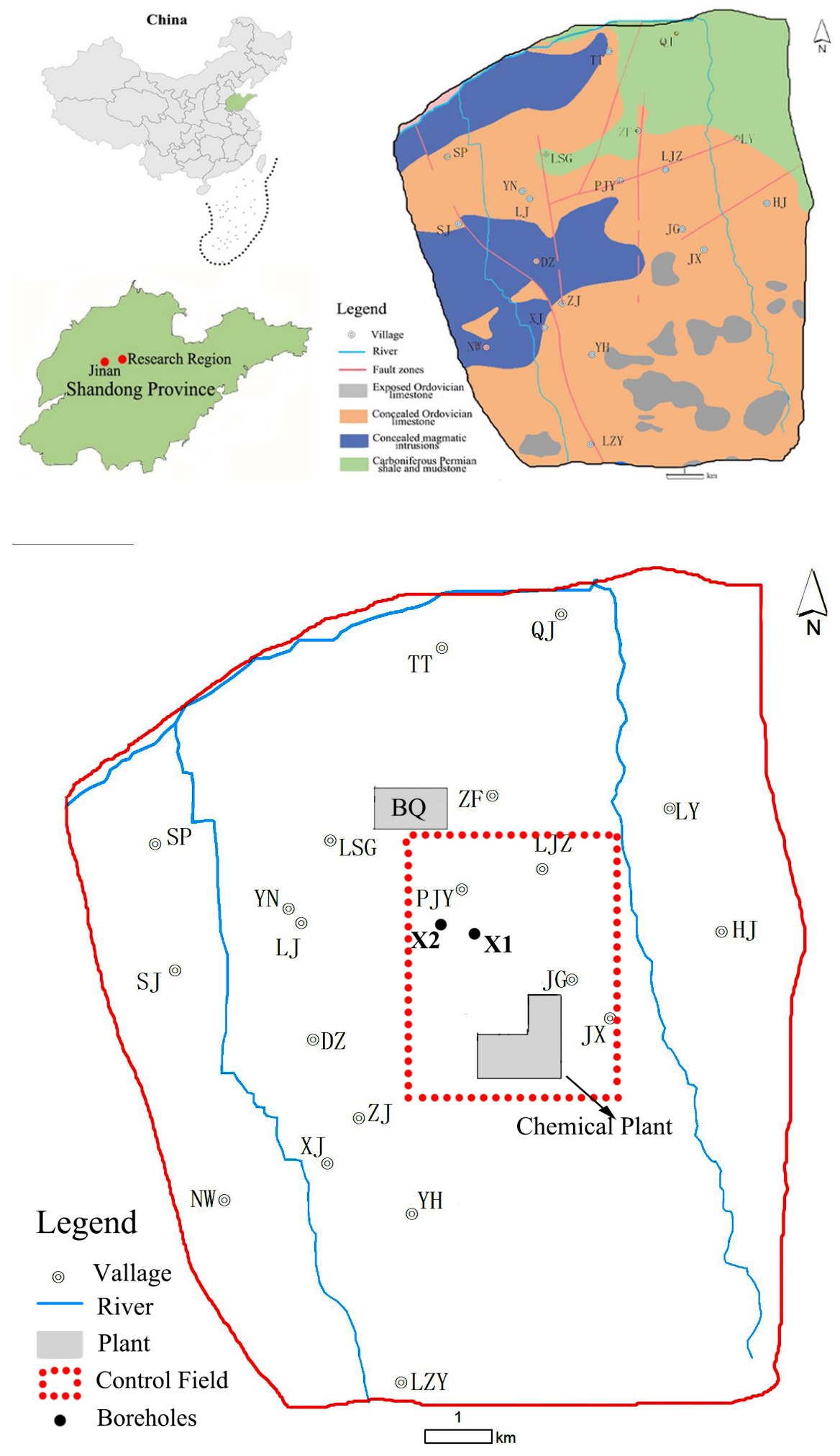

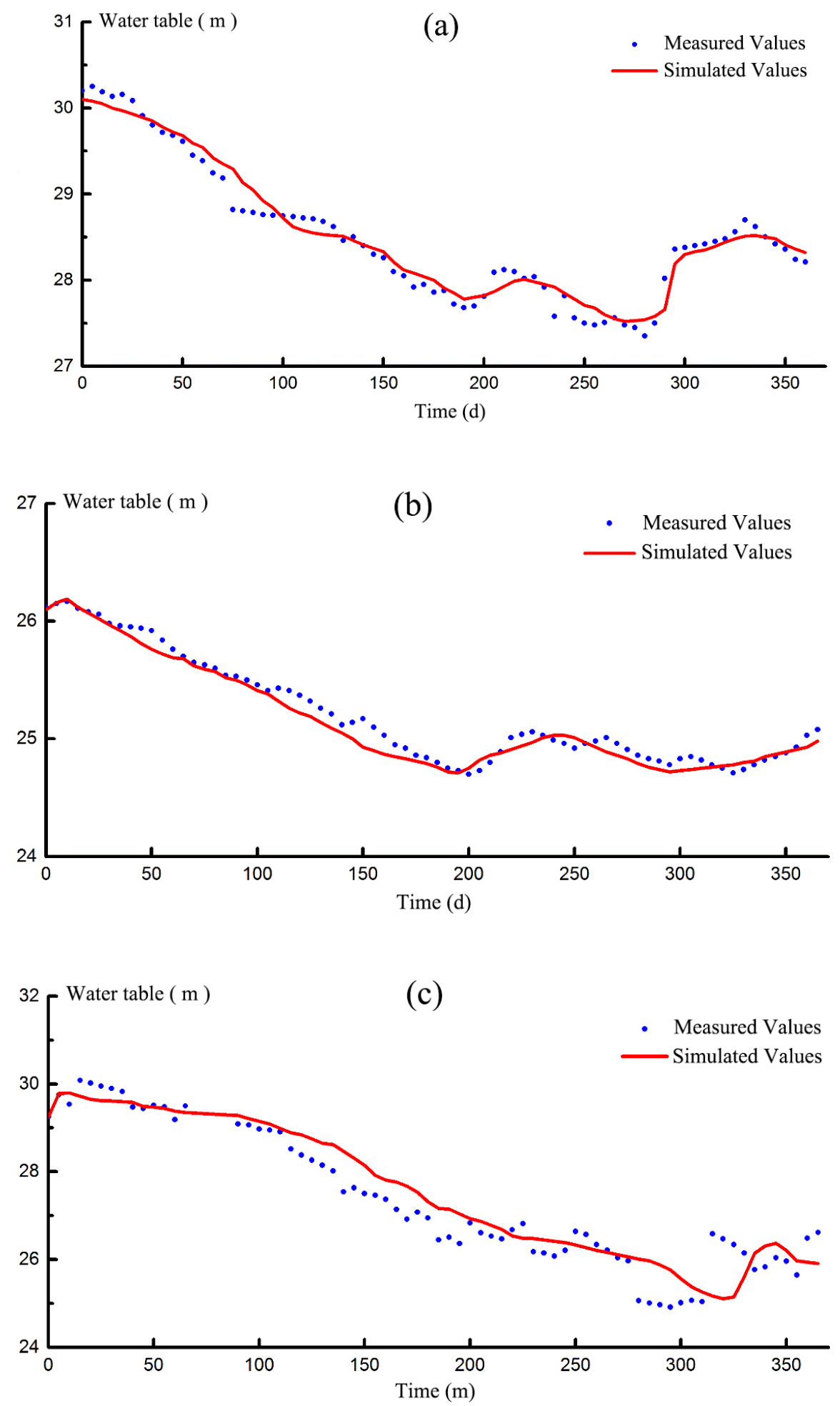

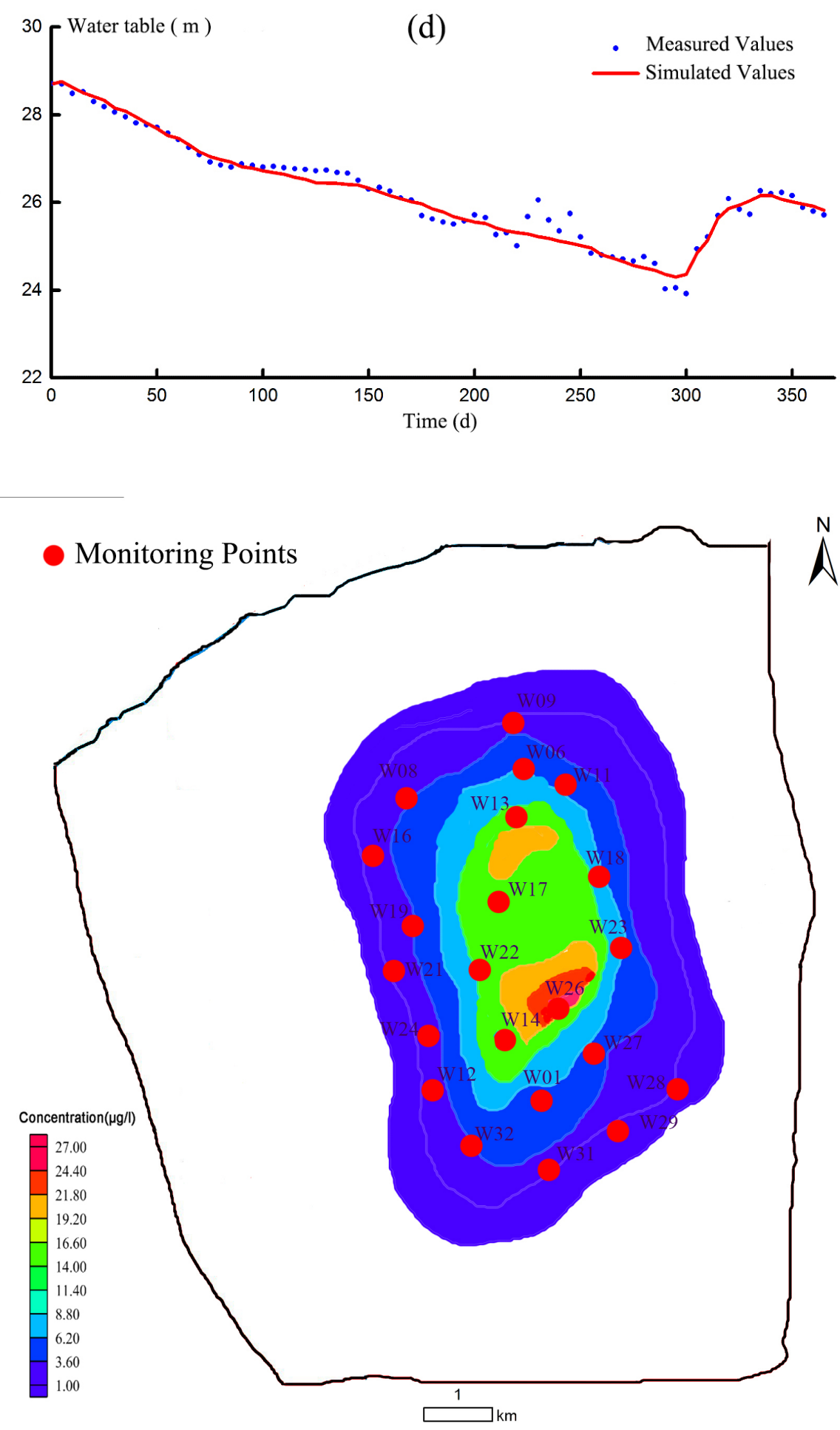

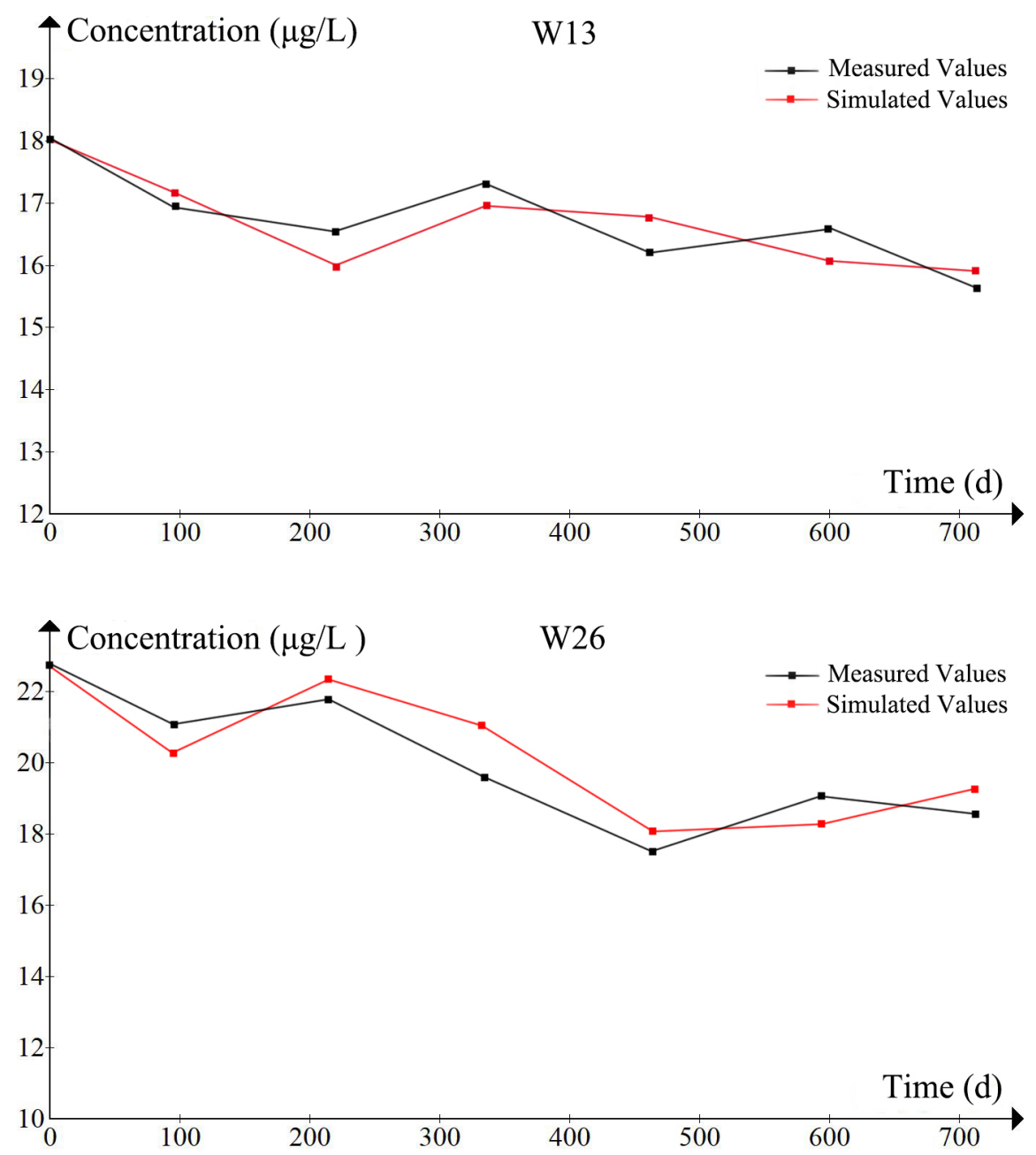


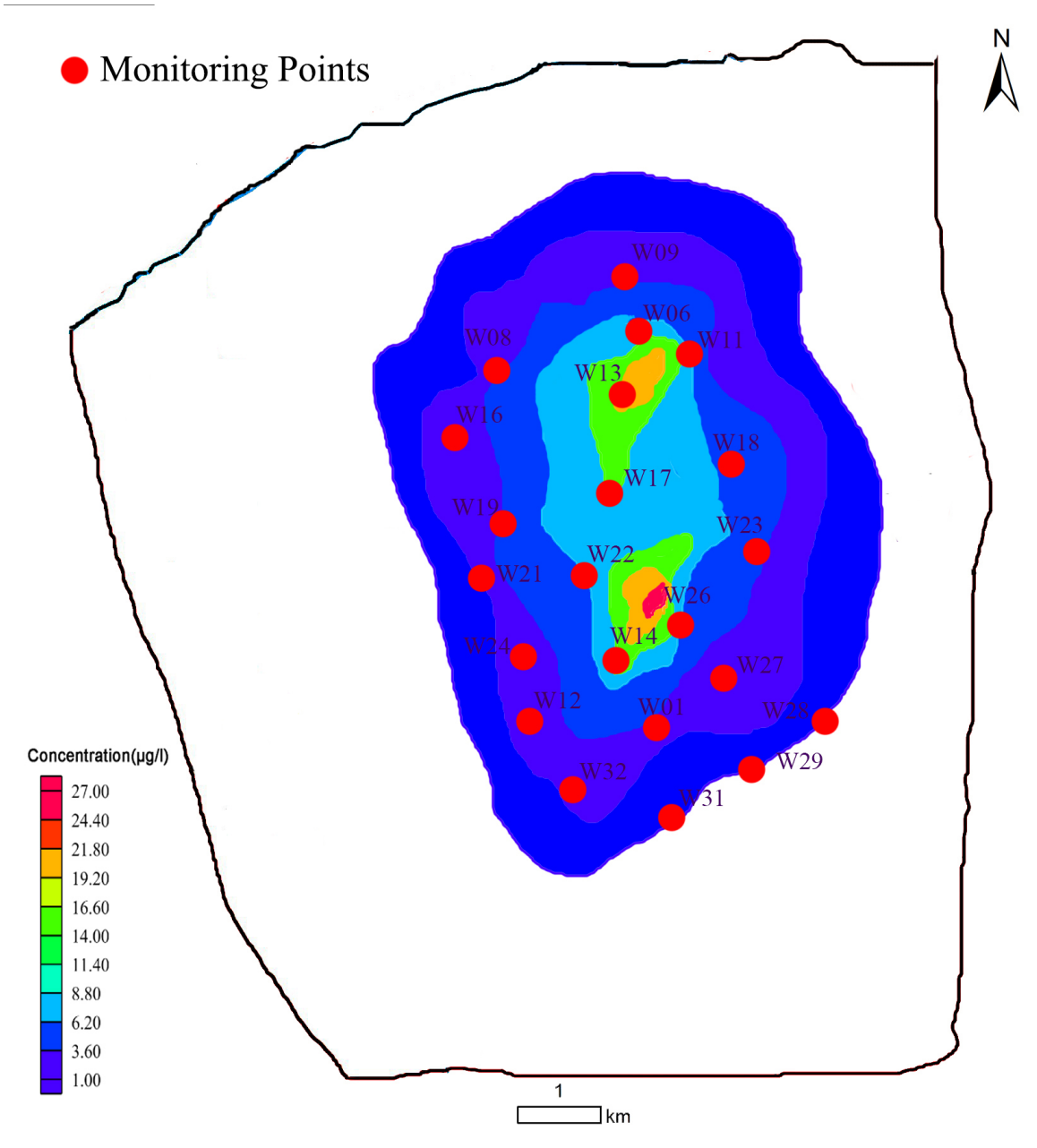




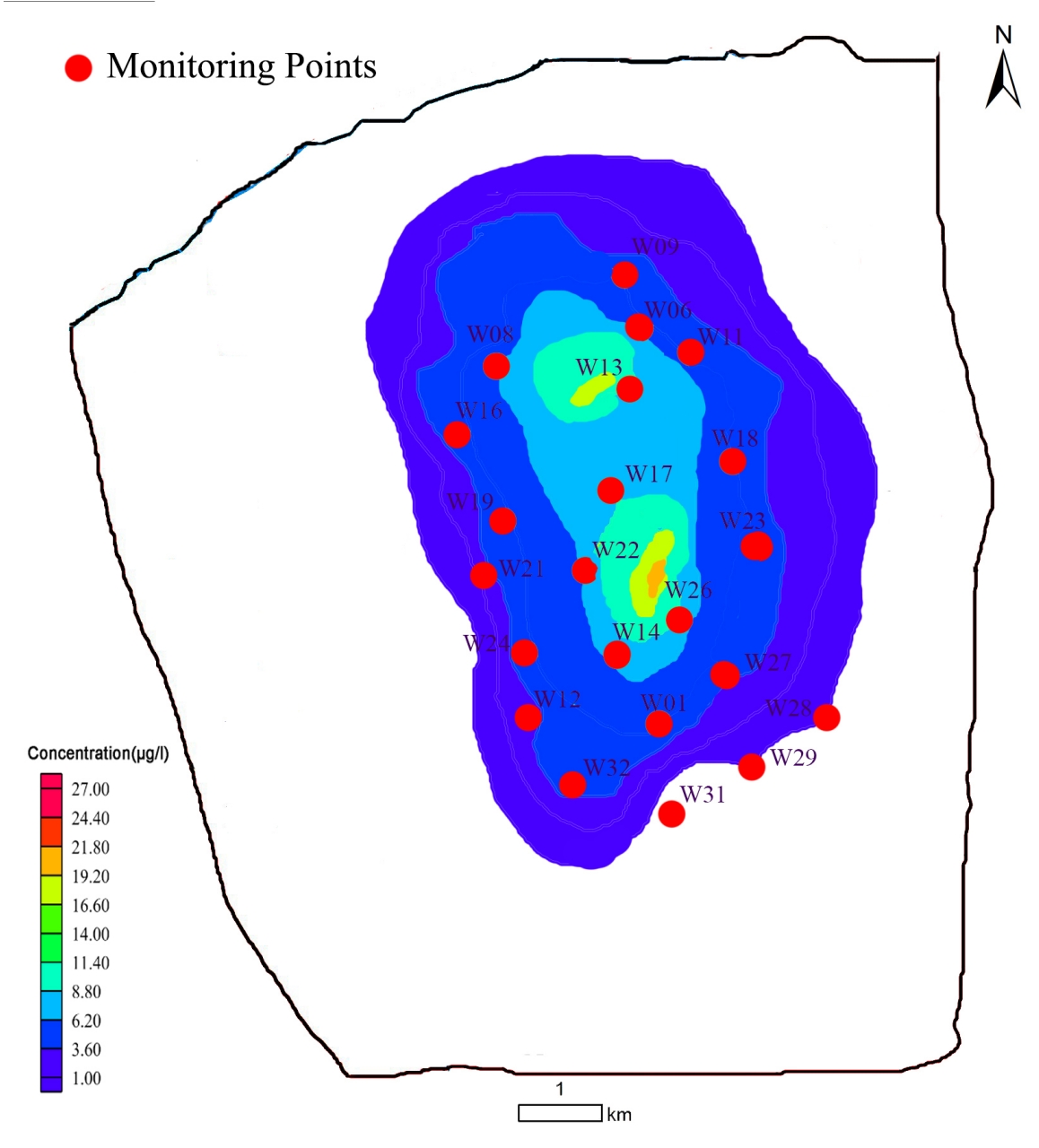



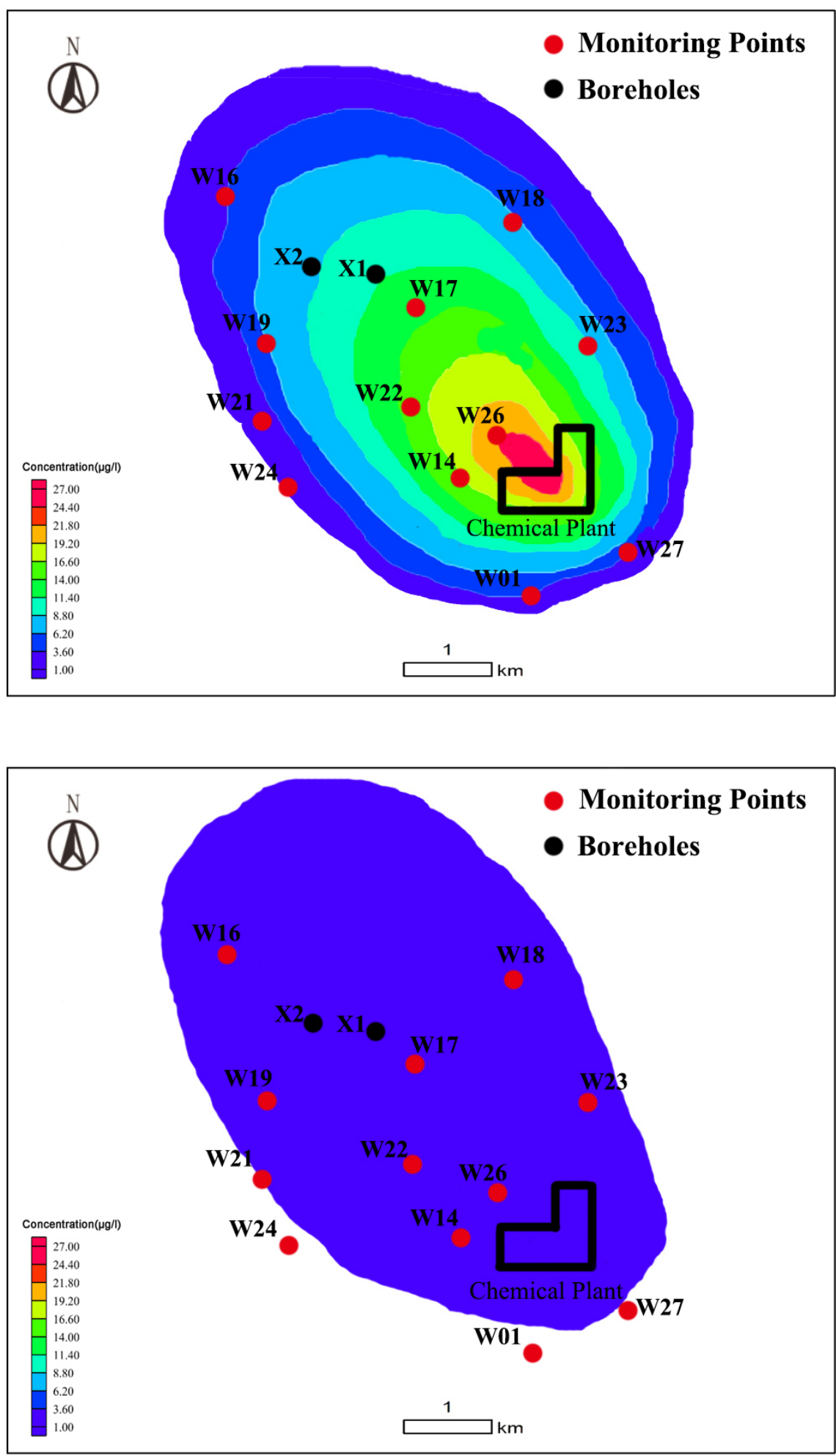

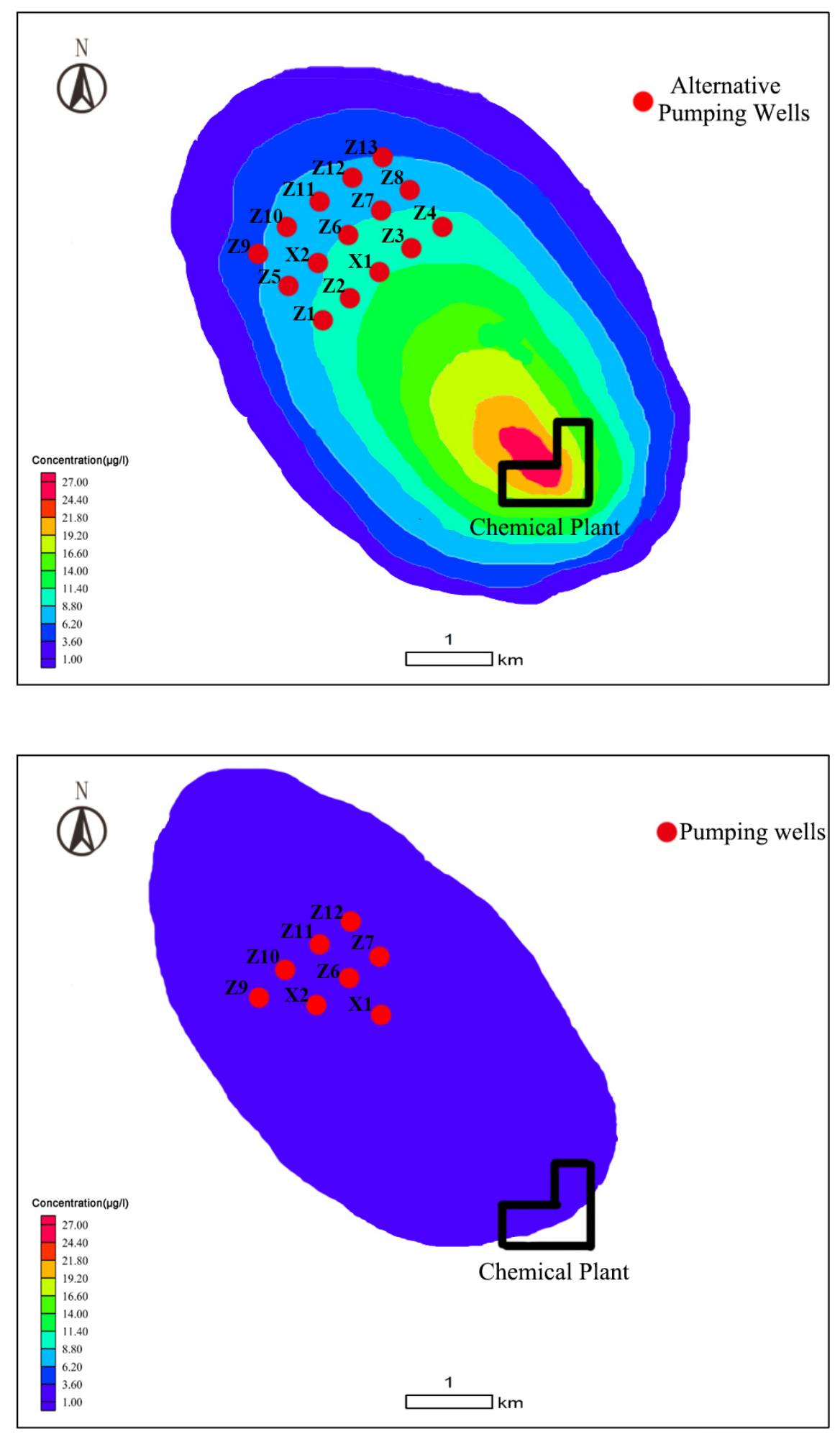

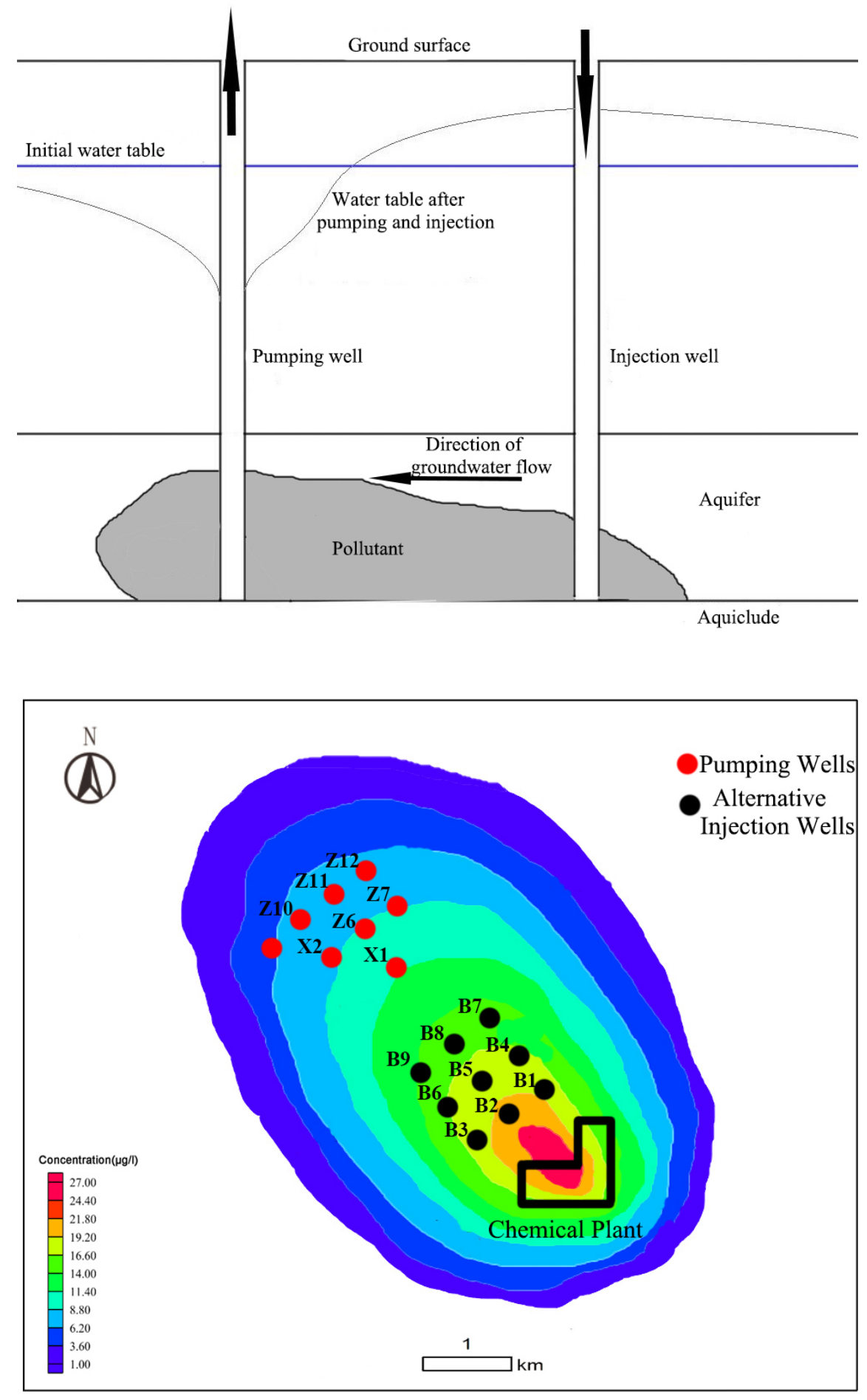

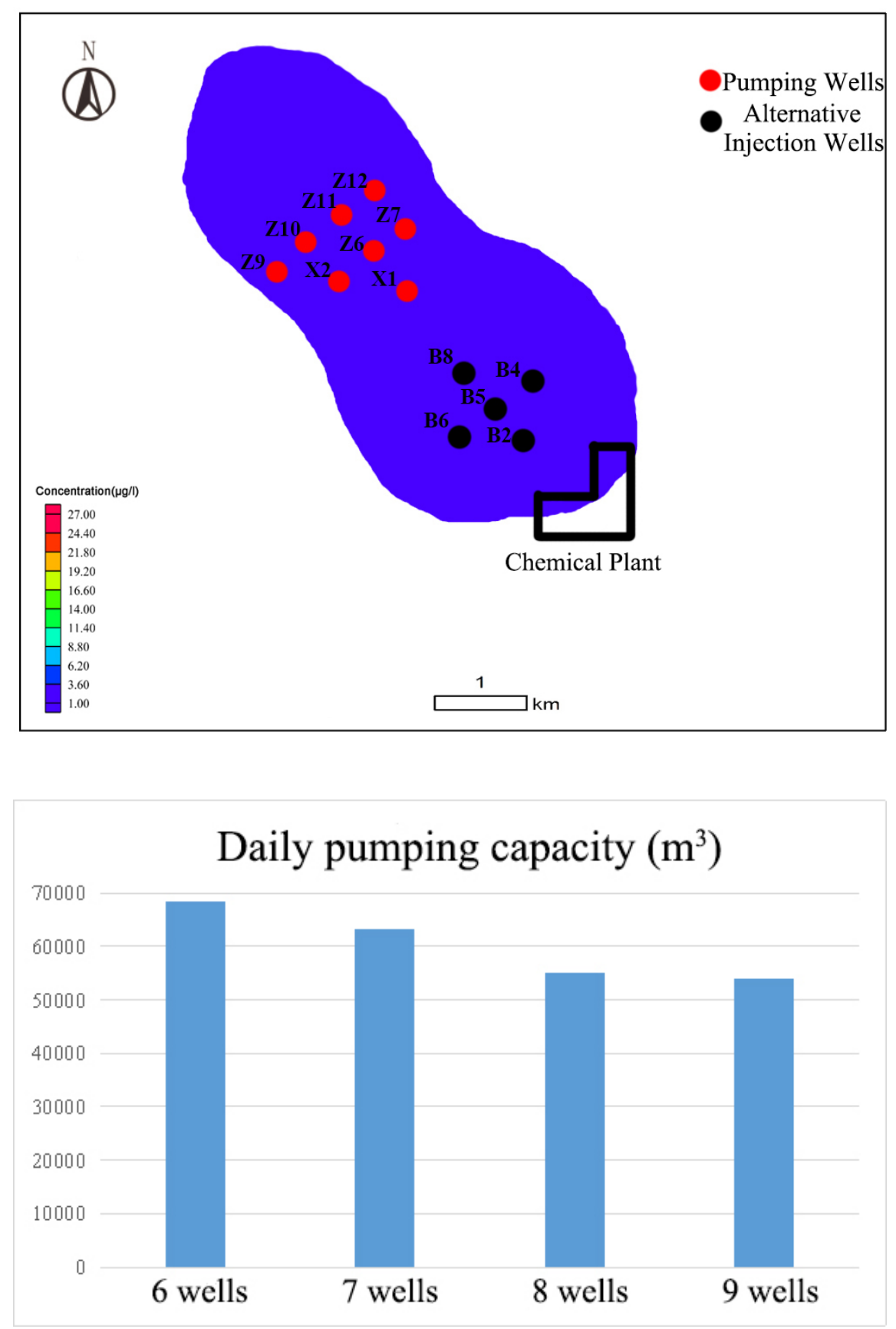


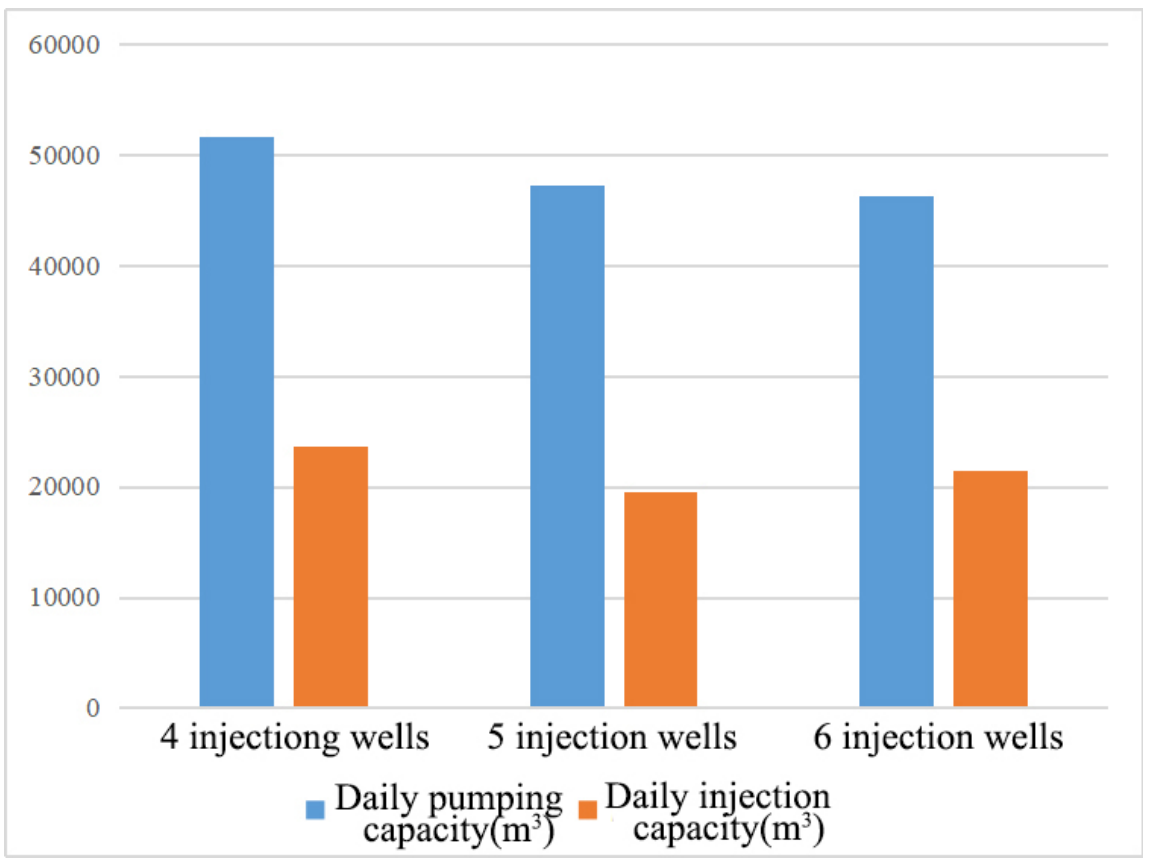

\section{Hosted file}

Table 1.docx available at https://authorea.com/users/446102/articles/545432-migration-andpollution-control-of-chlorinated-hydrocarbons-in-groundwater-system-of-eastern-jinan

\section{Hosted file}

Table 2 .docx available at https://authorea.com/users/446102/articles/545432-migration-andpollution-control-of-chlorinated-hydrocarbons-in-groundwater-system-of-eastern-jinan

\section{Hosted file}

Table 3 .docx available at https://authorea.com/users/446102/articles/545432-migration-andpollution-control-of-chlorinated-hydrocarbons-in-groundwater-system-of-eastern-jinan 